\title{
Induced Nematic Phase of New Synthesized Laterally Fluorinated Azo/Ester Derivatives
}

\author{
Fowzia S. Alamro ${ }^{1}$, Hoda A. Ahmed ${ }^{2,3, *}{ }^{\mathbb{D}}$, Mohamed A. El-Atawy ${ }^{3,4, *}$, , Salma A. Al-Zahrani ${ }^{5}$ \\ and Alaa Z. Omar ${ }^{4}$
}

1 Department of Chemistry, College of Science, Princess Nourah bint Abdulrahman University, Riyadh 11671, Saudi Arabia; fsalamro@pnu.edu.sa

2 Department of Chemistry, Faculty of Science, Cairo University, Cairo 12613, Egypt

3 Chemistry Department, Faculty of Science, Taibah University, Yanbu 46423, Saudi Arabia

4 Chemistry Department, Faculty of Science, Alexandria University, P.O. Box 426 Ibrahemia, Alexandria 21321, Egypt; alaazaki@alexu.edu.eg

5 Department of Chemistry, College of Sciences, University of Ha'il, Ha'il 2440, Saudi Arabia; s.alzahrane@uoh.edu.sa

* Correspondence: ahoda@sci.cu.edu.eg (H.A.A.); mohamed.elatawi@alexu.edu.eg (M.A.E.-A.)

Citation: Alamro, F.S.; Ahmed, H.A.; El-Atawy, M.A.; Al-Zahrani, S.A.;

Omar, A.Z. Induced Nematic Phase of New Synthesized Laterally Fluorinated Azo/Ester Derivatives. Molecules 2021, 26, 4546. https://doi.org/10.3390/ molecules26154546

Academic Editor: Borislav Angelov

Received: 10 July 2021

Accepted: 26 July 2021

Published: 28 July 2021

Publisher's Note: MDPI stays neutral with regard to jurisdictional claims in published maps and institutional affiliations.

Copyright: (c) 2021 by the authors. Licensee MDPI, Basel, Switzerland. This article is an open access article distributed under the terms and conditions of the Creative Commons Attribution (CC BY) license (https:/ / creativecommons.org/licenses/by/ $4.0 /)$.

\begin{abstract}
A new series of laterally fluorinated mesomorphic compounds, namely 2-fluoro-4-((4(alkyloxy)phenyl)diazenyl)phenyl 4-substitutedbenzoate $\left(\mathbf{I n}_{\mathbf{x}}\right)$ were prepared and evaluated for their mesophase behavior. The synthesized series constitutes five members that possess different terminally attached polar groups (X). Their molecular structures were confirmed by elemental analyses and both FT-IR and NMR spectroscopy. Examination of the prepared derivatives was conducted via experimental and theoretical tools. Mesomorphic investigations were carried by polarized optical microscopy (POM) and differential scanning calorimetry (DSC). DSC and POM measurements indicated that except for the un-substituted analogue, all other derivatives were purely nematogenic, possessing their nematic $(\mathrm{N})$ mesophase enantiotropically. This is to say that insertions of terminal polar substituents on their mesogenic structures induced the $\mathrm{N}$ phase. In addition, the location of lateral and terminal polar moieties played a considerable role in achieving good thermal $\mathrm{N}$ stability. Computational calculations were investigated to determine the deduced optimized molecular structures. Theoretical data indicated that both size and polarity of the terminal substituent $(X)$ have essential impact on the thermal parameters and optical properties of possible geometries.
\end{abstract}

Keywords: phase behaviour; lateral fluorine; induced nematic phase; optimize structure; DFT

\section{Introduction}

The thermal stability of azobenzenes and the possibility for their molecular-mobility in response to light and heat make them suitable for many photonic applications [1-6]. Additionally, their rigidity and linear geometry make them ready to exhibit liquid crystalline phenomena $[7,8]$. They can also produce photoactive mesomorphic materials, whereby they can easily undergo photo-induced trans/cis isomerization. Among many mesogenic linkages, azobenzenes are the most widely documented [9-20].

Changing the core structure or insertion of lateral substituents to azobenzene-based molecules affects marked differences in their photophysical and thermal properties [6,7]. The introduction of lateral groups with different volumes and polarities broadly improves many properties of liquid crystal (LC) materials. This is attributed to the disturbance in the molecular packing which drops the melting transition and thermal mesophase stability of LCs [21-28]. Anisotropic molecules are produced from the overall molecular geometry of architectures and the combination of both rigid and flexible chains. On the other hand, as the terminal flexible chain length increases, the molecules tend to be oriented in parallel 
arrangements [29]. Modification of the behaviors of LCs will impact the mesomorphism and their characteristics considered essential for many technological fields. Moreover, their lateral or terminal polar group significantly affects the mesomeric characters of the azobenzene derivatives.

Today, computational quantum chemistry of newly constructed materials has attracted attention for its many potential applications [30-43]. The DFT method is a good performance theoretical tool and gives excellent computational results. The mutual enhancement of many geometrical parameters requires predicted information of their molecular orbital energies. DFT calculations will provide a prediction of molecular geometry in the gas phase. Thus the presence of the molecule in a condensed mesophase will lead to a slight difference in the resulting energy. Consequently, more elongated species will be preferred $[38,44]$.

Insertion of the F-atom, as a lateral group, offers new mesomorphic behavior for the investigated LC derivatives [45-48] which is mainly dependent on the position and orientation of the F-atom. The high polarity and small volume of the F-atom enables it to enhance the mesomorphic and geometrical properties of the prepared LC compound such as its melting point, mesophase transitions, dipole moments, and dielectric anisotropy [49-52].

Recently, a homologous series possessing lateral F moiety [48] was synthesized and their mesomorphic behavior was investigated. These investigated derivatives and their two terminal wings are of flexible long chains. These compounds were found to exhibit $\mathrm{N}$ mesophases, and the position of F-atom in the molecular structure center was found to influence the physical and geometrical parameters of the molecules. In other studies [53-61], the investigation was directed toward measuring the impact of incorporation of lateral moiety on their mesomorphic properties in the terminal or central benzene rings.

The goal of the present study is to focus on synthesizing new azo/ester liquid crystalline systems possessing a lateral F-atom in their central cores and unsymmetrical terminals, namely 2-fluoro-4-((4-(alkyloxy)phenyl)diazenyl)phenyl 4-fluorobenzoate $\left(\mathbf{I n}_{\mathbf{x}}\right.$, Scheme 1), and to discuss their mesomorphic and geometrical parameters. We also investigate the effect of the location of the lateral F-atom and the length of terminal alkoxy chain (as well as the other different terminal compact groups) on the type and the stability of the formed mesophase. This study also aims to investigate the effect of the predicted computational DFT parameters on the optimized structures and determine how these parameters could affect their mesomorphic properties.<smiles>[X]c1ccc(C(=O)Oc2ccc(N=Nc3ccc(OC[14CH3])cc3)cc2F)cc1</smiles>

$\mathbf{I n}_{\mathbf{x}}$

$n=8$ or $16 \quad a, X=\mathrm{OCH}_{3} ; b, X=\mathrm{CH}_{3} ; c, X=H ; d, X=C l ; e, X=F$.

Scheme 1. Homologous series, $\mathbf{I n}_{\mathbf{x}}$.

\section{Experimental}

Synthesis of 2-Fluoro-4-((4-(alkyloxy)phenyl)diazenyl)phenyl 4-Substitutedbenzoate $\mathbf{I n}_{\boldsymbol{x}}$

The mesomorphic compounds $\mathbf{I n}_{\mathbf{x}}$ were synthesized according to Scheme 2 and all spectra of derivatives are depicted in Figures S1-S6 (Supplementary data): 


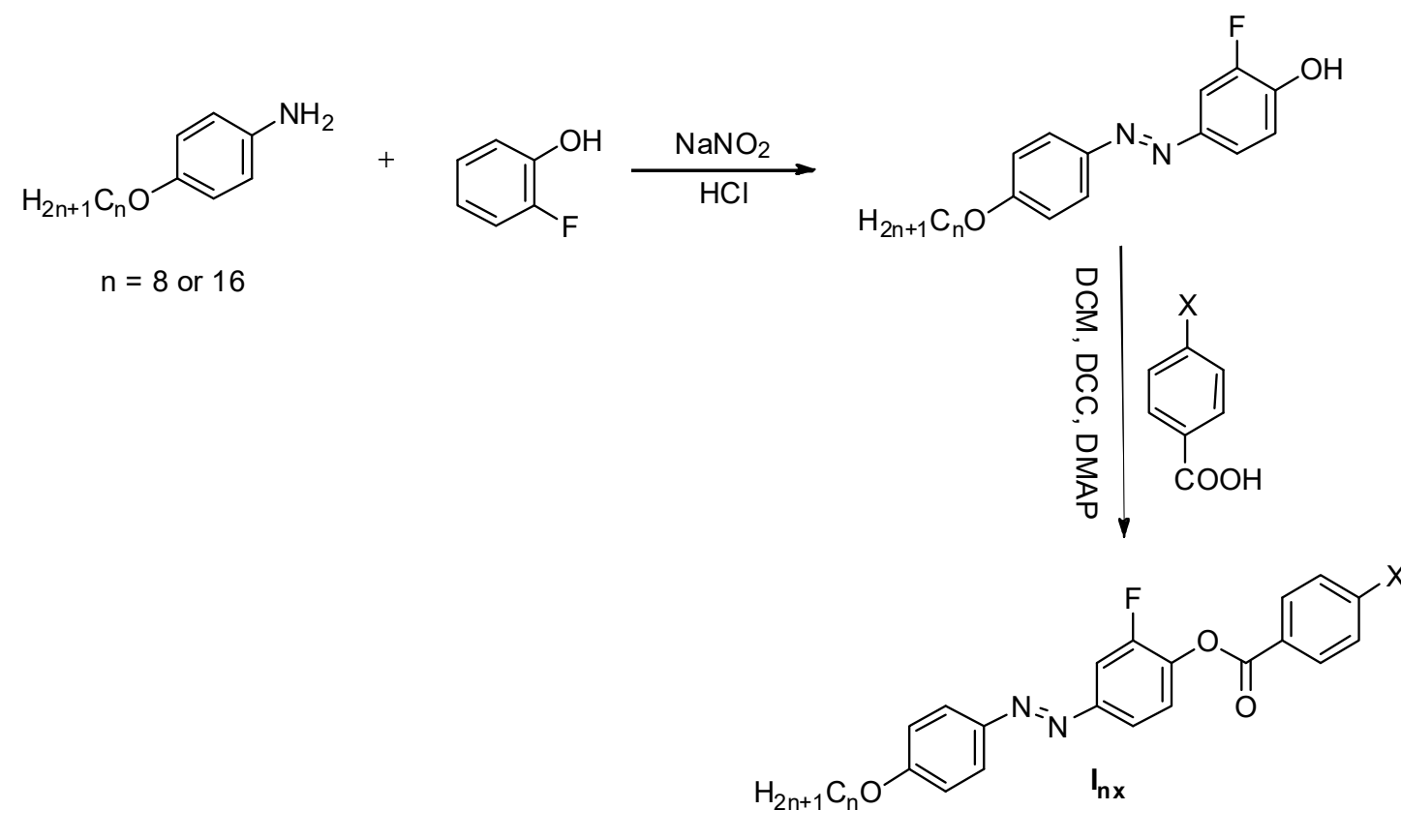

$\mathrm{n}=8$ or $16 \quad \mathrm{a}, \mathrm{X}=\mathrm{OMe} ; \mathrm{b}, \mathrm{X}=\mathrm{Me} ; \mathrm{c}, \mathrm{X}=\mathrm{H} ; \mathrm{d}, \mathrm{X}=\mathrm{Cl} ; \mathrm{e}, \mathrm{X}=\mathrm{F}$.

Scheme 2. Synthesis of 2-fluoro-4-((4-(alkyloxy)phenyl)diazenyl)phenyl 4-substituted benzoate $\mathbf{I n}_{\mathbf{x}}$.

\section{Results and Discussion}

\subsection{Mesomorphic and Optical Properties}

Details of the mesophase transitions of all of the evaluated homologues $\mathbf{I n}_{\mathbf{x}}$ series, as measured via DSC, are collected in Table 1. The types of phases, identified by POM for the present homologues, are in agreement with their DSC results. Figure 1, a representative example, depicted the DSC thermogram of $\mathbf{I}_{\mathbf{d}}$, taken as second heating/cooling rounds. The $\mathbf{N}$ phase schlieren textures of compounds $\mathbf{I 8}_{\mathbf{d}}$ and $\mathbf{I} \mathbf{1 6}_{\mathbf{b}}$ observed under POM are displayed in Figure 2. Phase transition temperatures of all of the derivatives are graphically displayed in Figure 3 in order to investigate the effect of terminal alkoxy-chain length ( $n=8$ and 16) on the mesomorphic properties in each group bearing different terminal polar substituent $X$.

Table 1. Mesomorphic temperature of transitions $\left(T^{\circ} \mathrm{C}\right)$, enthalpy of transition $\Delta H, \mathrm{~kJ} / \mathrm{mole}$, and normalized entropy of transition $\Delta S / \mathrm{R}$ for investigated set, $\mathbf{I n}_{\mathbf{x}}$.

\begin{tabular}{|c|c|c|c|c|c|c|c|c|c|c|c|c|}
\hline Comp & $X$ & $T_{\text {Cr-I }}$ & $\Delta H_{\mathrm{Cr}-\mathrm{I}}$ & $T_{\mathrm{Cr}-\mathrm{SmC}}$ & $\Delta H_{\mathrm{Cr}-\mathrm{SmC}}$ & $T_{\mathrm{Cr}-\mathrm{N}}$ & $\Delta H_{\mathrm{Cr}-\mathrm{N}}$ & $T_{\text {SmC-N }}$ & $\Delta H_{\text {SmC-N }}$ & $T_{\mathrm{N}-\mathrm{I}}$ & $\Delta H_{\mathrm{N}-\mathrm{I}}$ & $\Delta S / R$ \\
\hline I $8_{a}$ & $\stackrel{-}{\mathrm{OCH}_{3}}$ & - & - & 96.3 & 45.15 & - & - & 116.2 & 2.80 & 175.2 & 1.94 & 0.52 \\
\hline $18_{b}$ & $-\mathrm{CH}_{3}$ & - & - & - & - & 127.9 & 51.76 & - & - & 160.8 & 2.13 & 0.59 \\
\hline $\mathrm{I} 8_{\mathrm{c}}$ & $-\mathrm{H}$ & 105.3 & 57.64 & - & - & - & - & - & - & - & - & - \\
\hline I8 $8_{\mathrm{d}}$ & $-\mathrm{Cl}$ & - & - & - & - & 123.7 & 46.70 & - & - & 224.3 & 2.09 & 0.51 \\
\hline $18_{e}$ & $-F$ & - & - & - & - & 96.3 & 39.38 & - & - & 177.3 & 1.23 & 0.33 \\
\hline I16 & $\mathrm{OCH}_{3}$ & - & - & 87.6 & 48.78 & - & - & 128.5 & 2.90 & 164.5 & 1.48 & 0.41 \\
\hline $116_{b}$ & $-\mathrm{CH}_{3}$ & - & - & - & - & 106.9 & 44.6 & - & - & 135.7 & 1.62 & 0.48 \\
\hline $\mathrm{I16}_{\mathrm{c}}$ & $-\mathrm{H}$ & 101.6 & 59.87 & - & - & - & - & - & - & - & - & - \\
\hline $\mathrm{I16}_{\mathrm{d}}$ & $-\mathrm{Cl}$ & - & - & - & - & 116.9 & 46.32 & - & - & 220.2 & 1.87 & 0.46 \\
\hline I16 & $-F$ & - & - & - & - & 103.1 & 42.30 & - & - & 137.1 & 1.36 & 0.40 \\
\hline
\end{tabular}

$\mathrm{Cr}-\mathrm{N}$ refers to the solid-to-nematic phase. N-I refers to the nematic-to-isotropic liquid phase. 


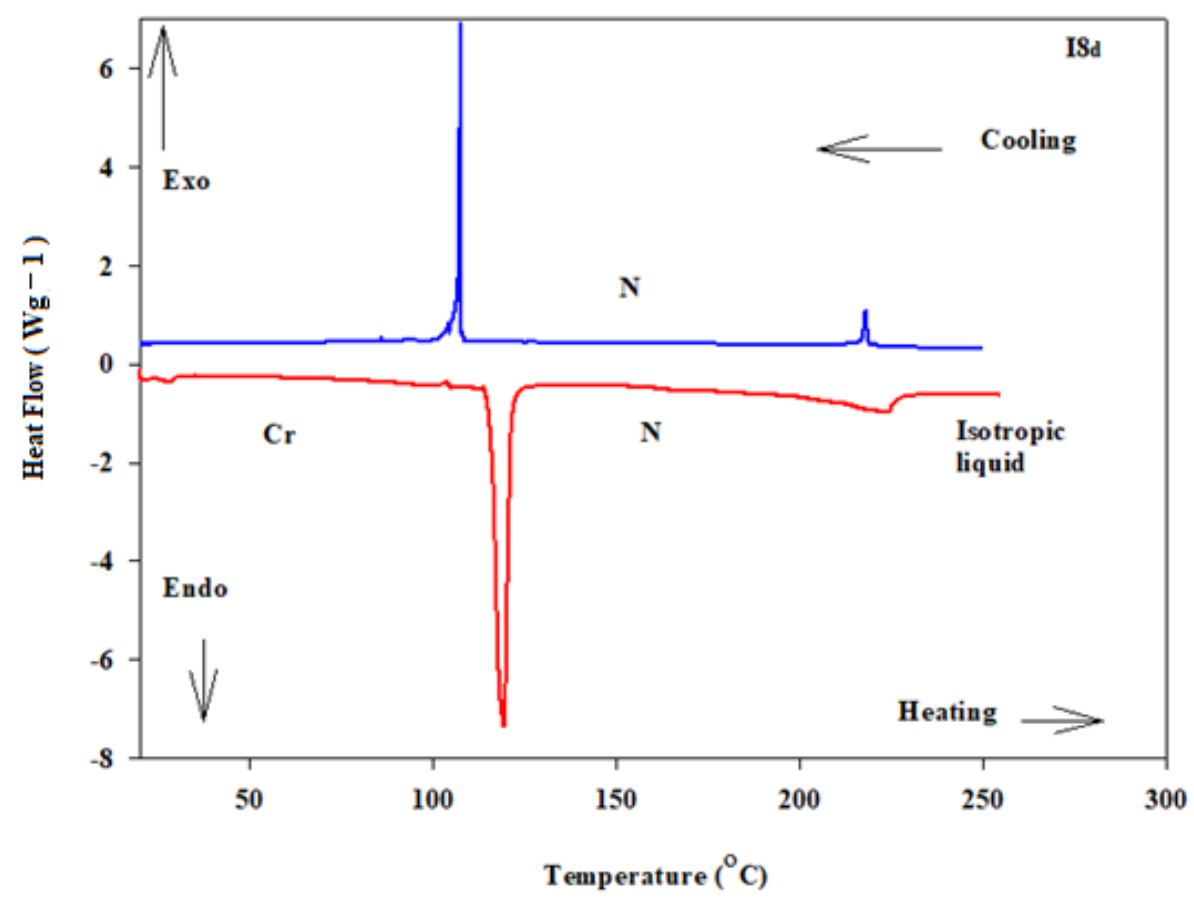

Figure 1. DSC thermograms captured from the second heating/cooling scan at heating rate $10^{\circ} \mathrm{C} / \mathrm{min}$ of compound $\mathbf{I} \mathbf{8}_{\mathrm{d}}$.

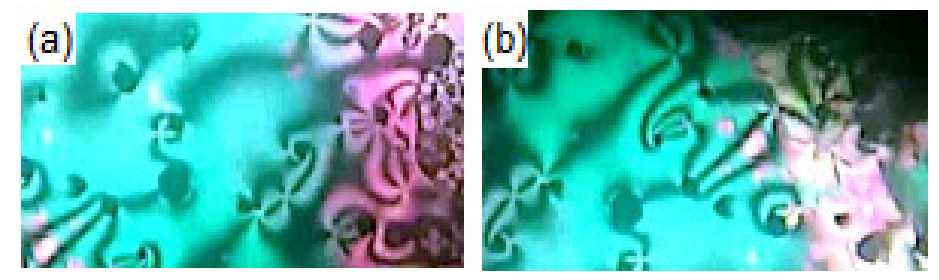

Figure 2. Images $(320 \times 97 \mathrm{px})$ of $\mathrm{N}$ phases under POM observed on heating for compounds (a) $\mathbf{I}_{\mathbf{d}}$ at $190.0{ }^{\circ} \mathrm{C}$ and $(\mathbf{b}) \mathbf{I 1 6}_{\mathbf{b}}$ at $120.0^{\circ} \mathrm{C}$.

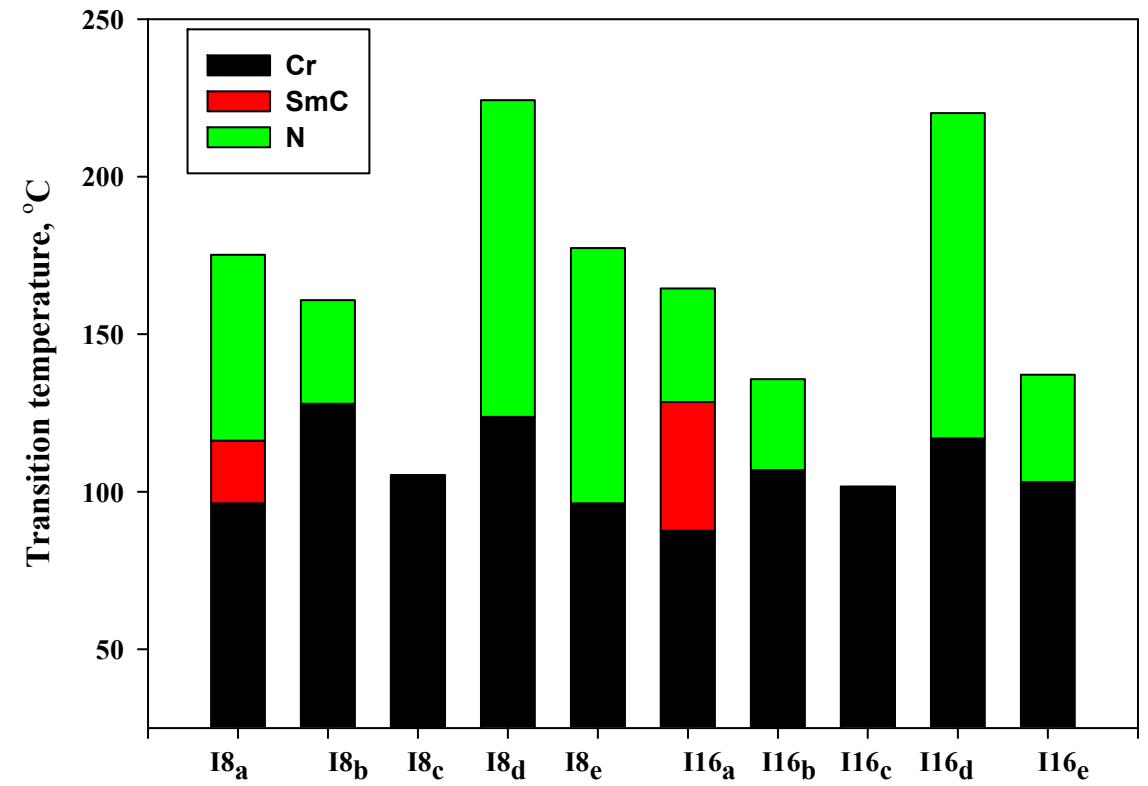

Figure 3. Effect of terminal (X) on the phase behavior of the investigated series $\mathbf{I n}_{\mathbf{x}}$. 
The results of Table 1 and Figure 3 revealed that the melting transitions of both homologues ( $\mathbf{I} \mathbf{8}_{\mathbf{x}}$ and $\mathbf{I 1 6}_{\mathbf{x}}$ ) have irregular trends. Melting temperature depends on the polarizability of the molecule as well as its geometrical structure. Moreover, all the compounds of the homologous series are enantiotropic, exhibiting mesophase thermal stability and mesomorphic temperature range depending on their terminal group $X$, except for the un-substituted derivatives $\left(\mathbf{I}_{\mathbf{c}}\right.$ and $\mathbf{I 1 6}_{\mathbf{c}}$ ) which show non-mesomorphic behaviors. In case of the electron-donating terminal methoxy substituted homologues $\left(\mathbf{I n}_{\mathbf{a}}\right)$, both compounds are dimorphic possessing enantiotropic SmC and $\mathrm{N}$ mesophases. The SmC range $\left(\Delta T_{\mathrm{SmC}}=T_{\mathrm{SmC}}-T_{\mathrm{cr}}\right)$ increases from $19.9-40.9^{\circ} \mathrm{C}$ with increasing the length of terminal alkoxy chain from $n=8$ to $n=16$, while the nematic range $\left(\Delta T_{\mathrm{N}}=T_{\text {iso }}-T_{\text {SmC }}\right)$ is dropped from $59.0-36.0^{\circ} \mathrm{C}$ as the alkoxy chain length increases from 8 to 16 carbons. It was documented that the nematic thermal stability decreases with $n[62,63]$. Thus, the derivative of shortest terminal-chain $\left(\mathbf{I}_{\mathrm{a}}\right)$ exhibits a higher $\mathrm{N}$ thermal stability value $\left(175.2{ }^{\circ} \mathrm{C}\right)$ than the higher homologue $\mathbf{I 1 6}_{\mathbf{a}}$, which possesses an $\mathrm{N}$ stability value of about $\left(164.5^{\circ} \mathrm{C}\right)$. The two homologues possess smectic $\mathrm{C}$ stabilities 116.2 and $128.5^{\circ} \mathrm{C}$ for $\mathbf{I}_{\mathbf{a}}$ and $\mathbf{I 1 6}_{\mathbf{a}}$, respectively. Homologues with the terminal $\mathrm{CH}_{3}$ group $\left(\mathbf{I n}_{\mathbf{b}}\right)$ are found to be monomorphic, possessing only the $\mathrm{N}$ phase. On the other hand, $\Delta T_{\mathrm{N}}$ is decreased from $32.9-28.8^{\circ} \mathrm{C}$ with an increasing $n$ from 8 to 16 . Additionally, the thermal $\mathrm{N}$ stability is reduced from $160.8-135.7^{\circ} \mathrm{C}$ as the terminal length increases from $n=8$ to $n=16$. In the case of the unsubstituted homologues $\left(X=H, \mathbf{I}_{\mathbf{c}}\right)$, all of the homologues exhibit non-mesomorphic behaviors, irrespective of their terminal alkoxy chain length. Moreover, only one endotherms characteristic peak of the crystal-to-isotropic transitions was observed in DSC measurements upon heating and reversed during the cooling cycle for $\mathbf{I n}_{\mathbf{c}}$. In addition, the POM investigations showed no mesophase textures, affirming that the materials do not exhibit any mesomorphic properties.

Electron-withdrawing terminally substituted $\mathrm{Cl}$ homologues $\left(\mathbf{I n}_{\mathbf{d}}\right)$ showed the broadest nematic temperature range and stability. The $\mathrm{N}$ phase stability and temperature range for $\mathbf{I} 8_{\mathrm{d}}$ reached values of 224.3 and $100.6^{\circ} \mathrm{C}$, respectively. By increasing the length of the terminal chain to $n=16\left(\mathbf{I 1 6}_{\mathbf{d}}\right)$, the $\mathrm{N}$ phase stability was slightly reduced to $220.2^{\circ} \mathrm{C}$ and the nematogenic temperature range became $103.3^{\circ} \mathrm{C}$. In the case of the small size terminal F-atom derivatives $\left(\mathbf{I n}_{\mathbf{e}}\right)$, the compounds were also purely nematogenic and exhibited only the $\mathrm{N}$ mesophase. Moreover, $\Delta T_{\mathrm{N}}$ was reduced from 81.0 to $34{ }^{\circ} \mathrm{C}$ and the $\mathrm{N}$ stability was reduced from 177.3 to $137.1^{\circ} \mathrm{C}$ with an increase of $n$ from 8 to 16 carbons. The descending trend in the $\mathrm{N}$ thermal stability can be ascribed to the dilution of the rigid mesogenic portion.

Based on the above results, the thermal $\mathrm{N}$ phase stability declined in the following order: $\mathrm{Cl}>\mathrm{F}>\mathrm{OCH}_{3}>\mathrm{CH}_{3}$ for $\mathbf{I 8}_{\mathbf{x}}$, and $\mathrm{Cl}>\mathrm{OCH}_{3}>\mathrm{F}>\mathrm{CH}_{3}$ for $\mathbf{I 1 6}_{\mathbf{x}}$, while the un-substituted homologues $\left(\mathbf{I n}_{\mathbf{c}}\right)$ were non-mesomorphic. Thus, the introduction of the terminal polar group induced the mesophase when incorporated in the mesogenic structure. In general, the polarity of the attached-groups, aspect-ratio, polarizability, molecular rigidity, and shape of the molecule are considered to be essential factors responsible for the thermal stability and range of the formed mesophases and their texture types. The factors that affect the mesophase properties will be briefly discussed in the next section of theoretical calculation studies.

The normalized entropy changes of mesophase transitions $(\Delta S / R)$ for all designed laterally F members $\left(\mathbf{I n}_{\mathbf{x}}\right)$ are collected in Table 1. Data indicate that, independent of the terminal substituents, the N-I entropy transitions showed irregular trend and lower values. Their relatively small magnitudes may be due to the somewhat molecular biaxiality and the relatively high values of clearing temperatures, which in turn reduced the N-I entropy changes [64-66]. The configuration of the lateral F-atom plays a considerable role in the physical and geometrical parameters of the molecule. This will be briefly discussed in the theoretical work of this study. Additionally, the azo moiety thermal cis/trans isomerization leads to lower entropy changes, as has been determined before (for example, see [65,67-69]). 


\subsection{Computational Calculations}

\subsubsection{Thermal and Geometrical Parameters}

The geometry of a compound is an inherent property which dictates other properties showcased by the molecule. Based on this, the optimized geometrical structure of each member of the present series $\left(\mathbf{I n}_{\mathbf{x}}\right)$ was determined in order to establish the most stable geometry for the molecule. The results are presented in Figure 4. Theoretical calculations were carried out via the DFT method for all of the designed derivatives in order to correlate the predated quantum chemical parameters and the experimental findings. Computational calculations were performed in the gas phase with DFT/B3LYP program at basis set $6-311 G^{* *}$. The designed homologues $\left(\mathbf{I n}_{\mathbf{x}}\right)$ ere proved to exist in planar conformation since they possessed mesomorphic characters, except for the unsubstituted derivatives which are non-mesomorphic. Zero-point energy and other predicted thermal parameters are summarized in Tables 2 and 3. It was found that all of the estimated parameters increased with an increasing of the terminal alkoxy-chain length from $n=8$ to $n=16$. Moreover, these parameters normally changed according to the type of the terminal group (X). All compounds show linear and planar shapes, as displayed in Figure 4. It was documented in [70] that the mesogenic core planarity of the mesomorphic molecules is influenced by the mesomeric-nature of the polar attached moieties. Thus, the conjugated $\pi$-cloud interactions resulting from the polar lateral $\mathrm{F}$ and terminal $\mathrm{X}$ groups played a considerable role in inducing mesomorphic phenomena with good physical parameters.
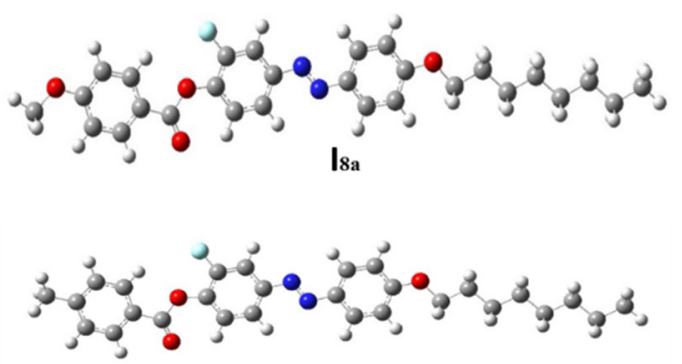

$I_{8 b}$

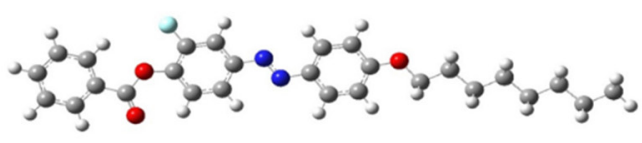

I8c

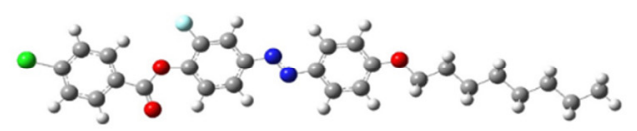

I8d

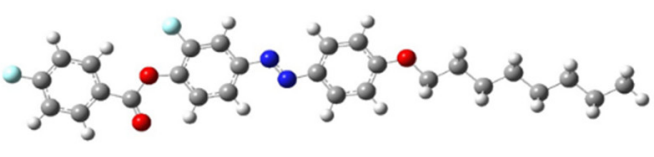

Ise
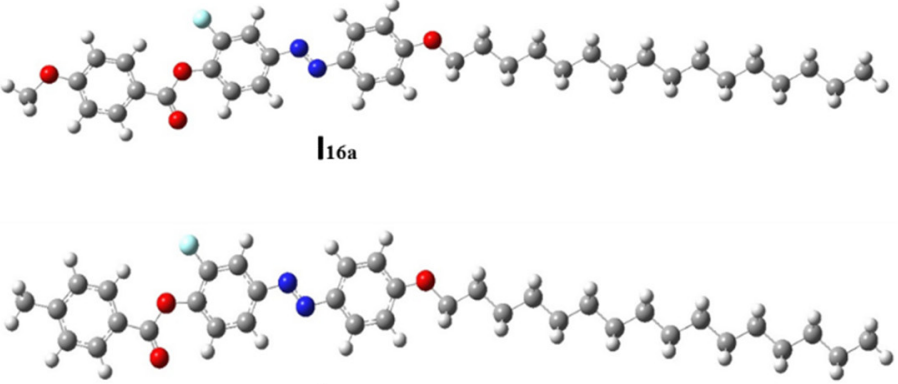

l16b

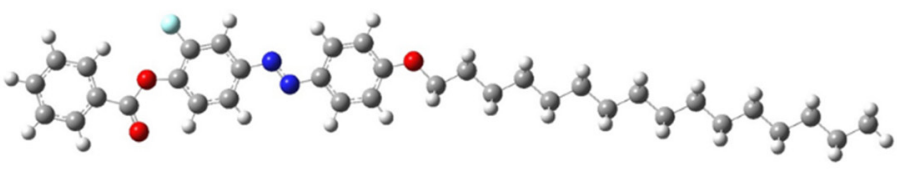

$I_{16 c}$
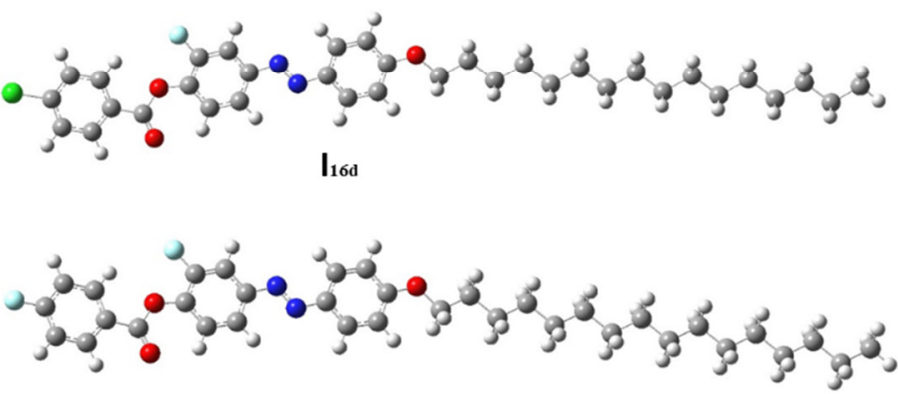

$I_{16 e}$

Figure 4. The optimized molecular structures of analogues series $\operatorname{In}_{\mathbf{x}}$, predicted at B3LYP /6-311G ${ }^{* *}$ level. 
Table 2. Estimated thermal parameters for present series, $\mathbf{I n}_{\mathbf{x}}$.

\begin{tabular}{cccccc}
\hline Compound & $\begin{array}{c}\text { ZPE } \\
\text { (Kcal/Mol) }\end{array}$ & $\begin{array}{c}\text { Thermal } \\
\text { Energy } \\
\text { (Kcal/Mol) }\end{array}$ & $\begin{array}{c}\text { Enthalpy } \\
\text { (Kcal/Mol) }\end{array}$ & $\begin{array}{c}\text { Gibbs Free } \\
\text { Energy } \\
\text { (Kcal/Mol) }\end{array}$ & $\begin{array}{c}\text { Entropy (Cal } \\
\text { mol·k) }\end{array}$ \\
\hline $\mathbf{I 8}_{\mathbf{a}}$ & 339.931 & 360.875 & 361.467 & 295.216 & 222.206 \\
$\mathbf{I}_{\mathbf{b}}$ & 336.987 & 358.034 & 358.627 & 290.124 & 229.761 \\
$\mathbf{I}_{\mathbf{c}}$ & 319.853 & 339.674 & 340.266 & 275.311 & 217.862 \\
$\mathbf{I}_{\mathbf{d}}$ & 313.578 & 334.225 & 334.818 & 267.740 & 224.983 \\
$\mathbf{I}_{\mathbf{e}}$ & 314.447 & 334.832 & 335.424 & 269.207 & 222.091 \\
$\mathbf{I 1 6}_{\mathbf{a}}$ & 483.249 & 511.573 & 512.165 & 426.784 & 286.371 \\
$\mathbf{I 1 6}_{\mathbf{b}}$ & 480.291 & 507.554 & 508.147 & 425.184 & 278.260 \\
$\mathbf{I 1 6}_{\mathbf{c}}$ & 463.181 & 489.788 & 490.381 & 408.976 & 273.032 \\
$\mathbf{I 1 6}_{\mathbf{d}}$ & 456.900 & 484.336 & 484.928 & 401.334 & 280.376 \\
$\mathbf{I 1 6}_{\mathbf{e}}$ & 457.772 & 484.943 & 485.536 & 402.825 & 277.414 \\
\hline
\end{tabular}

Table 3. Total Energy, $\mathrm{E}_{\mathrm{HOMO}}, \mathrm{E}_{\mathrm{LUMO}}, \Delta \mathrm{E}$, dipole moment, ionization energy, electron affinity, and polarizability for the investigated series, $\mathbf{I n}_{\mathbf{x}}$.

\begin{tabular}{|c|c|c|c|c|c|c|c|c|}
\hline \multicolumn{2}{|c|}{ Compound Total Energy (Ha) } & \multirow{2}{*}{$\begin{array}{c}\mathrm{E}_{\text {HOMO }}(\mathrm{ev}) \\
-6.043\end{array}$} & \multirow{2}{*}{$\begin{array}{c}\text { EluMo }_{\text {luev }} \\
-2.515\end{array}$} & \multirow{2}{*}{$\begin{array}{c}\Delta \mathrm{E}(\mathrm{ev}) \\
3.528\end{array}$} & \multirow{2}{*}{$\begin{array}{c}\begin{array}{c}\text { Dipole } \\
\text { Moment (D) }\end{array} \\
2.6252\end{array}$} & \multirow{2}{*}{$\frac{\text { IE (ev) }}{6.043}$} & \multirow{2}{*}{$\begin{array}{c}\text { EA (ev) } \\
2.515\end{array}$} & \multirow{2}{*}{$\begin{array}{c}\begin{array}{c}\text { Polarizability } \\
\text { Bohr }^{\mathbf{3}}\end{array} \\
424.26\end{array}$} \\
\hline I8 & -1595.223 & & & & & & & \\
\hline I $8_{b}$ & -1520.026 & -6.074 & -2.547 & 3.527 & 1.8676 & 6.074 & 2.547 & 414.42 \\
\hline $18_{c}$ & -1480.739 & -6.108 & -2.586 & 3.522 & 2.6458 & 6.108 & 2.586 & 396.84 \\
\hline $\mathrm{I} 8_{\mathrm{d}}$ & -1940.352 & -6.194 & -2.701 & 3.493 & 5.4948 & 6.194 & 2.701 & 414.23 \\
\hline 18 & -1579.994 & -6.175 & -2.668 & 3.507 & 5.0740 & 6.175 & 2.668 & 397.89 \\
\hline I16 & -1909.479 & -6.042 & -2.515 & 3.527 & 2.6315 & 6.042 & 2.515 & 519.56 \\
\hline$I 16_{b}$ & -1834.285 & -6.074 & -2.547 & 3.527 & 1.9022 & 6.074 & 2.547 & 509.61 \\
\hline I16 & -1794.997 & -6.107 & -2.586 & 3.521 & 2.6949 & 6.107 & 2.586 & 492.04 \\
\hline $\mathrm{I}^{1} 6_{\mathrm{d}}$ & -2254.610 & -6.193 & -2.701 & 3.492 & 5.5510 & 6.193 & 2.701 & 509.50 \\
\hline $116_{e}$ & -1894.251 & -6.174 & -2.667 & 3.507 & 5.1293 & 6.174 & 2.667 & 493.10 \\
\hline
\end{tabular}

As shown in Table 3, the lower magnitudes of predicted ionization potential (I.E) for the $\mathbf{I} \mathbf{n}_{\mathbf{a}}$ compounds indicate a more basic nature of the terminal $\mathrm{OCH}_{3}$ derivatives than other compounds in the prepared series [71]. Additionally, a pronounced increase of polarizability is observed for member $\mathbf{I 1 6} \mathbf{a}_{\mathbf{a}}$ that may be due to the increment of the molecular shape aspect ratio. In general, the polarity of the attached substituents, rigidity and polarizability as well as geometry of the mesomorphic molecule are considered important parameters for inducing and influencing the mesophase behavior. In addition, the thermal stability is mainly dependent on the length of the terminal chains [72].

\subsubsection{Frontier Molecular Orbitals (FMOs)}

The frontier molecular orbitals presented in Figure $5 \mathrm{a}, \mathrm{b}$ show that all compounds in the series $\left(\mathbf{I n}_{\mathbf{x}}\right)$ have different HOMO and LUMO distributions. For the HOMO, the electron clouds were evenly distributed over the carbon atoms and the $\pi$-electron of the two benzene rings bearing the lateral $\mathrm{F}$, as well as the linking groups. On the other hand, the LUMO distributions of electron clouds are extended to the third phenyl ring bearing the alkoxy chain. The resulting energies and energy gaps for the present investigated $\mathbf{I n}_{\mathbf{x}}$ series are collected in Table 3 . The HOMO and LUMO energy gap $(\Delta \mathrm{E})$ are both related to the chemical reactivity of the compounds. More reactive molecules have an energy gap with a lower magnitude. Predicted $\Delta \mathrm{E}$ (Table 3) confirms that the $\mathbf{I n}_{\mathbf{d}}$ derivatives $(\mathrm{X}=\mathrm{Cl})$ are more reactive than the other compounds. They are also softer than other members due to that fact that the $\Delta \mathrm{E}$ is inversely related to the softness. Furthermore, the FMO energy gaps are highly impacted by the orientation and location of the mesogens (ester and azo linkages). This orientation cloud allows for the maximum delocalization of the $\mathbb{I}$ -electrons, and thereby decreases the $\Delta \mathrm{E}$ of the FMOs. 


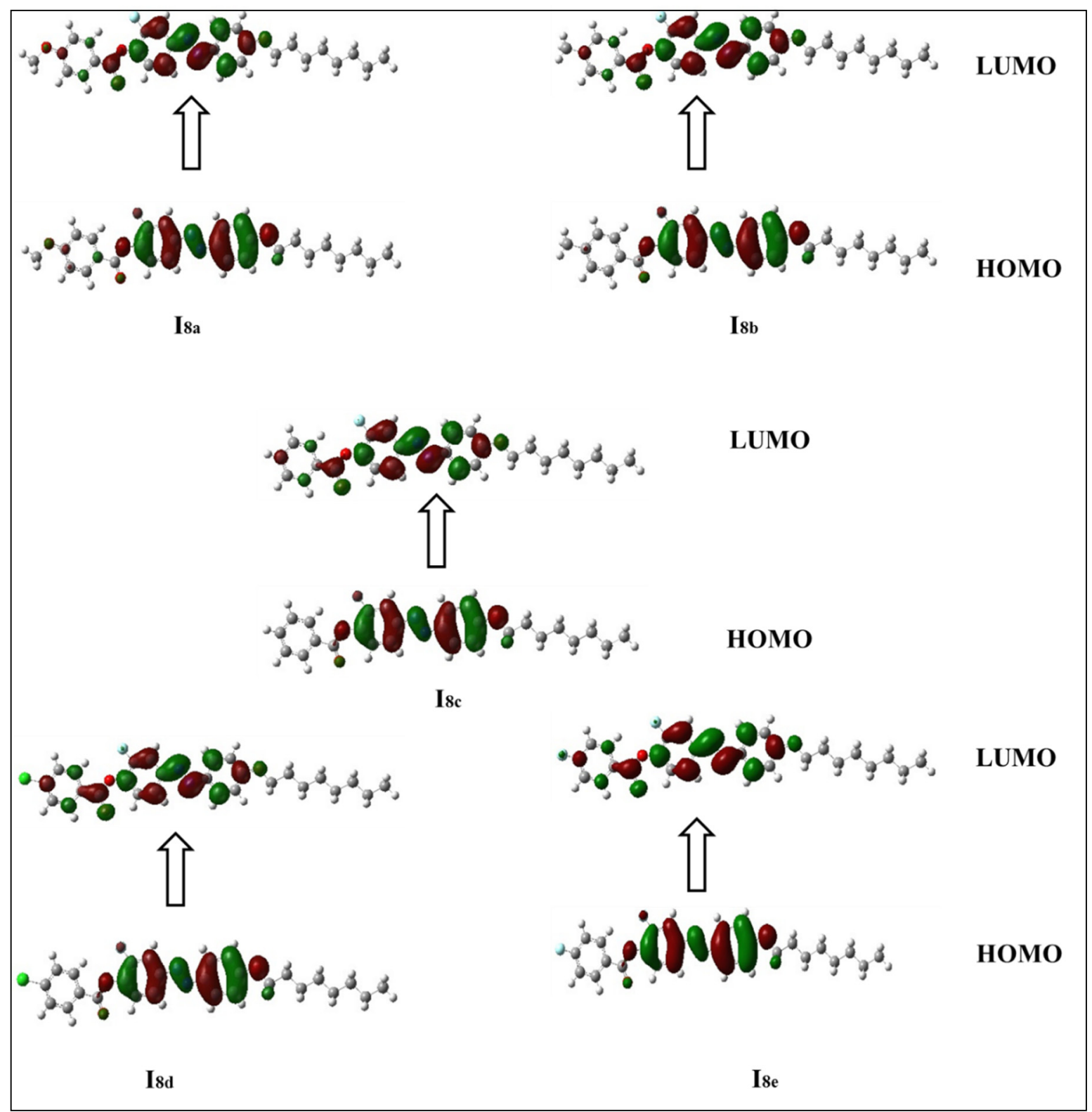

(a)

Figure 5. Cont. 


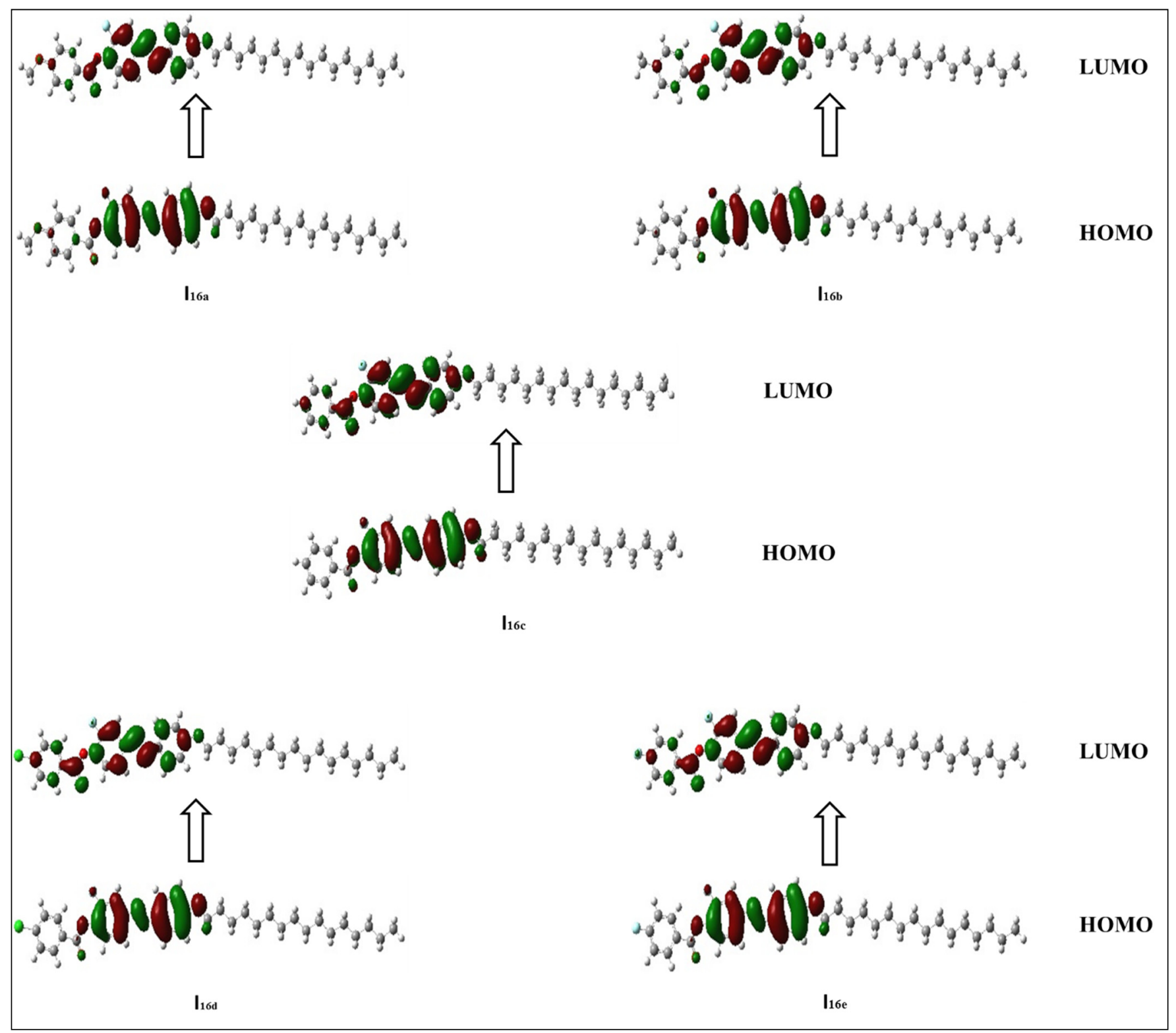

(b)

Figure 5. Estimated FMOs for of the synthesized analogues sets (a) $\mathbf{I} \mathbf{8}_{\mathbf{x}}$ and (b) $\mathbf{1} \mathbf{1 6}_{\mathbf{x}}$.

\subsubsection{Molecular Electrostatic Potential (MEP)}

The geometry of the prepared mesomorphic molecules was impacted by the mesomeric configurations, which were in turn affected by molecular-molecular interactions. The polarizability, electronic shape, dipole moment, and other parameters were impacted by the distribution of the electron density at the atomic sites of the liquid crystalline compounds [73]. MEP is considered to be one of the best tools for the estimation of the presence of inter-/intra-molecular interactions the evaluated molecules. The MEP of the present series $\left(\mathbf{I n}_{\mathbf{x}}\right)$ are shown in the Figure 6 . Here, the shadowing of carbonyl oxygen and the lateral F-atom by a red cloud suggests a low electrostatic potential but a high electron density for these regions. On the other hand, the blue cloud over the first alkoxy methylene and the neighboring phenyl hydrogen indicates low electron density but high electrostatic potential. Additionally, as the terminal chain length increases from $n=8$ to $n=16$, the polarizability of the molecule increases. This observation could be explained in the term of the less ordered nematic phase which covers all of the prepared molecules of terminal polar groups. Additionally, Figure 6 indicated that the location of mesogens and the electronic nature 
of the terminal polar X influenced the distribution of the MEP. Moreover, they appeared to impact the mesophase kind and stability by altering the competitive forces between end-end and side-side interactions. In recent studies, we have investigated the correlation between computational charge distribution and mesomorphic properties $[48,60,74,75]$. The increment of the charge distribution on the molecules is attributed either to the greater electron-donation or electron-acceptance of terminal aggregations to enhance the $\mathrm{N}$ phase or the parallel-interactions to predominate the semectic phase.

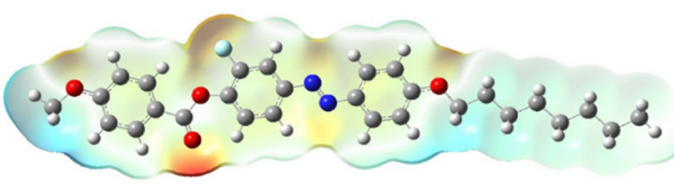

I8a

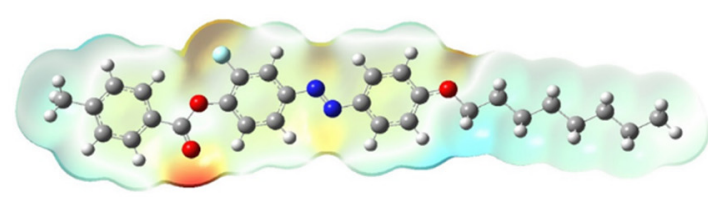

$I_{8 b}$

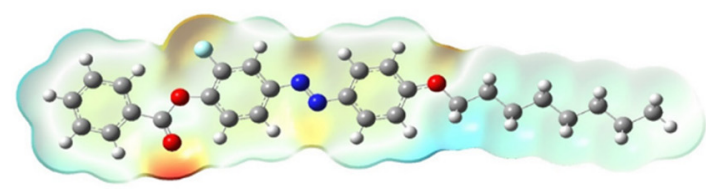

$I_{8 c}$

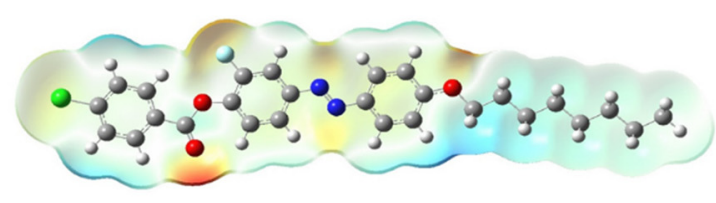

$I_{\mathbf{8 d}}$

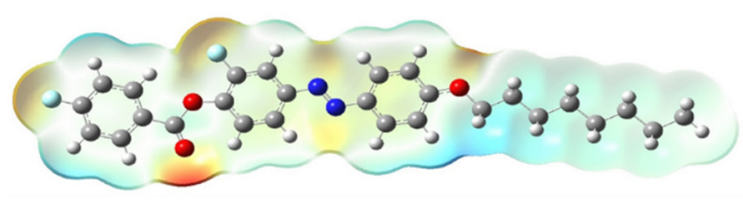

Ise

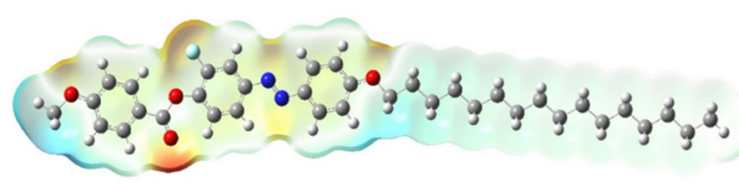

l16a

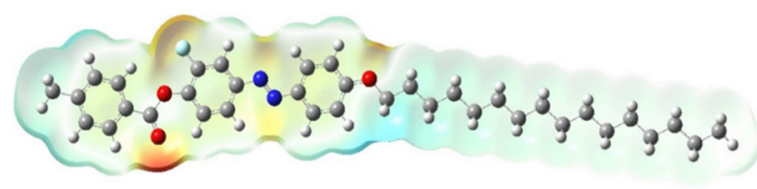

$l_{16 b}$

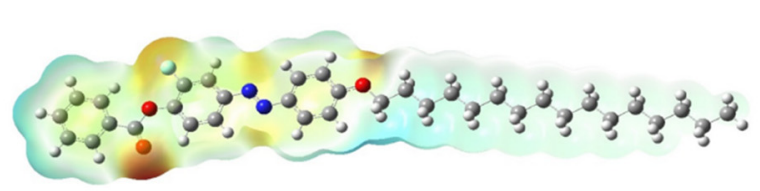

$\mathbf{1} 16 \mathrm{c}$

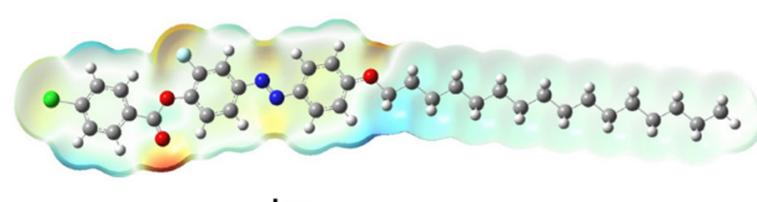

$l_{160}$

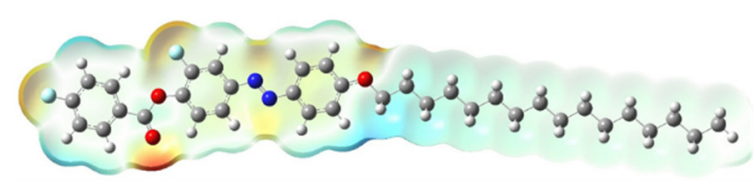

l16e

Figure 6. MEP of series, $\operatorname{In}_{\mathbf{x}}$.

\section{Conclusions}

New fluorinated liquid crystalline analogous series possessing different terminal polar compact groups, namely, 2-fluoro-4-((4-(alkyloxy)phenyl)diazenyl)phenyl 4substitutedbenzoate, were prepared and investigated for their properties via experimental and computational measurements. Their molecular structures were determined via different spectroscopic analyses. Both mesomorphic and optical examinations were measured using DSC and POM and revealed that all of the designed analogues are monomorphic and purely nematogenic with enantiotropic properties (except for the un-substituted analogues, which demonstrated non-mesomorphic behavior). The selected terminal polar electron donating and electron withdrawing groups contributed to achieving the induced $\mathrm{N}$ phase with good thermal stability. DFT theoretical calculations revealed that the lateral and terminal polar groups have essential effects on the stability of the predicted geometries and their thermal parameters. Moreover, the produced $\mathrm{N}$ mesophase was dependent on the 
influenced dipole moment of the mesogenic portion, which was in turn dependent on the geometrical shape of molecule.

Supplementary Materials: The following are available online. Figures S1-S6: Materials, Methods and spectroscopic analyses, Characterizations.

Author Contributions: Formal analysis, A.Z.O., H.A.A., F.S.A. and S.A.A.-Z.; Funding acquisition, F.S.A., H.A.A. and M.A.E.-A.; Methodology, M.A.E.-A., H.A.A. and A.Z.O.; Project administration, F.S.A.; Resources and Software, M.A.E.-A. and H.A.A.; Writing—original draft, H.A.A., A.Z.O., F.S.A., S.A.A.-Z. and M.A.E.-A.; Writing-review and editing, H.A.A., A.Z.O., F.S.A., S.A.A.-Z. and M.A.E.-A. All authors have read and agreed to the published version of the manuscript.

Funding: This research was funded by the Deanship of Scientific Research at Princess Nourah bint Abdulrahman University through the Fast-track Research Funding Program.

Institutional Review Board Statement: Not applicable.

Informed Consent Statement: Not applicable.

Data Availability Statement: Not applicable.

Acknowledgments: The authors acknowledge the Deanship of Scientific Research at Princess Nourah bint Abdulrahman University through the Fast-track Research Funding Program.

Conflicts of Interest: The authors declare no conflict of interest.

\section{References}

1. Ikeda, T.; $\mathrm{Wu}, \mathrm{Y}$. Photoinduced alignment behavior of polymer liquid crystals containing azobenzene moieties in the side chain. Pure Appl. Chem. 1999, 71, 2131-2136. [CrossRef]

2. Eich, M.; Wendorff, J.H.; Reck, B.; Ringsdorf, H. Reversible digital and holographic optical storage in polymeric liquid crystals. Die Makromol. Chem. Rapid Commun. 1987, 8, 59-63. [CrossRef]

3. Eich, M.; Wendorff, J.H. Erasable holograms in polymeric liquid crystals. Die Makromol. Chem. Rapid Commun. 1987, 8, 467-471. [CrossRef]

4. Anderle, K.; Birenheide, R.; Werner, M.J.A.; Wendorff, J.H. Molecular addressing? Studies on light-induced reorientation in liquid-crystalline side chain polymers. Liq. Cryst. 1991, 9, 691-699. [CrossRef]

5. Kato, T.; Mizoshita, N.; Kishimoto, K. Functional Liquid-Crystalline Assemblies: Self-Organized Soft Materials. Angeww. Chem. Int. Ed. 2006, 45, 38-68. [CrossRef] [PubMed]

6. Ikeda, T.; Mamiya, J.-I.; Yu, Y. Photomechanics of Liquid-Crystalline Elastomers and Other Polymers. Angew. Chem. Int. Ed. 2007, 46, 506-528. [CrossRef] [PubMed]

7. Ichimura, K. Photoalignment of Liquid-Crystal Systems. Chem. Rev. 2000, 100, 1847-1874. [CrossRef] [PubMed]

8. Ikeda, T. Photomodulation of liquid crystal orientations for photonic applications. J. Mater. Chem. 2003, 13, 2037-2057. [CrossRef]

9. Beharry, A.A.; Woolley, G.A. ChemInform Abstract: Azobenzene Photoswitches for Biomolecules. Chem. Soc. Rev. 2011, 42, 4422-4437. [CrossRef]

10. Tanaka, D.; Ishiguro, H.; Shimizu, Y.; Uchida, K. Thermal and photoinduced liquid crystalline phase transitions with a rod-disc alternative change in the molecular shape. J. Mater. Chem. 2012, 22, 25065-25071. [CrossRef]

11. Alaasar, M.; Poppe, S.; Tschierske, C. Photoresponsive halogen bonded polycatenar liquid crystals. J. Mol. Liq. 2019, 277, $233-240$. [CrossRef]

12. Iftime, M.-M.; Cozan, V.; Airinei, A.; Varganici, C.; Ailiesei, G.; Timpu, D.; Sava, I. Asymmetric azomethine amines with azobenzene moieties-liquid crystalline and optical properties. Liq. Cryst. 2019, 46, 1584-1594. [CrossRef]

13. Wang, M.; Han, Y.; Guo, L.-X.; Lin, B.-P.; Yang, H. Photocontrol of helix handedness in curled liquid crystal elastomers. Liq. Cryst. 2018, 46, 1231-1240. [CrossRef]

14. Gomha, S.; Ahmed, H.; Shaban, M.; Abolibda, T.; Khushaim, M.; Alharbi, K. Synthesis, Optical Characterizations and Solar Energy Applications of New Schiff Base Materials. Materials 2021, 14, 3718. [CrossRef] [PubMed]

15. Zhou, M.; Lu, H.; Zhang, X.; Zhang, Q.; Xu, M.; Zhu, J.; Zhang, G.; Ding, Y.; Qiu, L. Tuning helical twisting power and photoisomerisation kinetics of axially chiral cyclic azobenzene dopants in cholesteric liquid crystals. Liq. Cryst. 2019, 46, 2181-2189. [CrossRef]

16. Yu, Y.-B.; He, W.-L.; Jiang, Z.-M.; Yu, Z.-F.; Ren, L.; Lu, Y.; Yang, Z.; Cao, H.; Wang, D. The effects of azo-oxadiazole-based bent-shaped molecules on the temperature range and the light-responsive performance of blue phase liquid crystal. Liq. Cryst. 2019, 46, 1024-1034. [CrossRef]

17. Abberley, J.P.; Storey, J.; Imrie, C.T. Structure-property relationships in azobenzene-based twist-bend nematogens. Liq. Cryst. 2019, 46, 2102-2114. [CrossRef] 
18. Aya, S.; Salamon, P.; Paterson, D.A.; Storey, J.M.; Imrie, C.T.; Araoka, F.; Jákli, A.; Buka, Á. Fast-and-giant photorheological effect in a liquid crystal dimer. Adv. Mater. Interfaces 2019, 6, 1802032. [CrossRef]

19. Paterson, D.; Walker, R.; Abberley, J.P.; Forestier, J.; Harrison, W.T.A.; Storey, J.; Pociecha, D.; Gorecka, E.; Imrie, C. Azobenzenebased liquid crystal dimers and the twist-bend nematic phase. Liq. Cryst. 2017, 44, 2060-2078. [CrossRef]

20. Paterson, D.; Xiang, J.; Singh, G.; Walker, R.; Agra-Kooijman, D.M.; Martinez-Felipe, A.; Gao, M.; Storey, J.; Kumar, S.; Lavrentovich, O.D.; et al. Reversible Isothermal Twist-Bend Nematic-Nematic Phase Transition Driven by the Photoisomerization of an Azobenzene-Based Nonsymmetric Liquid Crystal Dimer. J. Am. Chem. Soc. 2016, 138, 5283-5289. [CrossRef]

21. Altowyan, A.; Ahmed, H.; Gomha, S.; Mostafa, A. Optical and Thermal Investigations of New Schiff Base/Ester Systems in Pure and Mixed States. Polymers 2021, 13, 1687. [CrossRef]

22. Khushaim, M.S.; Alalawy, H.H.; Naoum, M.M.; Ahmed, H.A. Experimental and computational simulations of nematogenic liquid crystals based on cinnamic acid in pure and mixed state. Liq. Cryst. 2021. [CrossRef]

23. Naoum, M.M.; Metwally, N.H.; Eltawab, M.M.A.; Ahmed, H.A. Polarity and steric effect of the lateral substituent on the mesophase behaviour of some newly prepared liquid crystals. Liq. Cryst. 2015, 42, 1351-1369. [CrossRef]

24. Ahmed, H.; Saad, G. Mesophase behaviour of laterally di-fluoro-substituted four-ring compounds. Liq. Cryst. 2015, 42, 1765-1772. [CrossRef]

25. Naoum, M.M.; Fahmi, A.A.; Ahmed, H.A. Effect of the Relative Orientation of the Two Fluoro-Substituents on the Mesophase Behavior of Phenylazophenyl Benzoates. Mol. Cryst. Liq. Cryst. 2012, 562, 43-65. [CrossRef]

26. Naoum, M.M.; Fahmi, A.A.; Ahmed, H.A. Liquid crystalline behaviour of model compounds di-laterally substituted with different polar groups. Liq. Cryst. 2011, 38, 511-519. [CrossRef]

27. Naoum, M.; Ahmed, H. Effect of dipole moment and conformation on the mesophase behavior of di-laterally substituted phenylazophenyl benzoate liquid crystals. Thermochim. Acta 2011, 521, 202-210. [CrossRef]

28. Naoum, M.M.; Mohammady, S.Z.; Ahmed, H.A. Lateral protrusion and mesophase behaviour in pure and mixed states of model compounds of the type 4-(4'-substituted phenylazo)-2-(or 3-)methyl phenyl-4'-alkoxy benzoates. Liq. Cryst. 2010, 37, 1245-1257. [CrossRef]

29. Dave, J.S.; Menon, M. Azomesogens with a heterocyclic moiety. Bull. Mater. Sci. 2000, 23, 237-238. [CrossRef]

30. Al-Mutabagani, L.; Alshabanah, L.; Gomha, S.; Ahmed, H. Synthesis, Thermal and Optical Characterizations of New Lateral Organic Systems. Crystals 2021, 11, 551. [CrossRef]

31. Alamro, F.S.; Gomha, S.M.; Shaban, M. Optical investigations and photoactive solar energy applications of new synthesized Schiff base liquid crystal derivatives. Sci. Rep. 2021, 11, 15046. [CrossRef] [PubMed]

32. Chen, R.; An, Z.; Wang, W.; Chen, X.; Chen, P. Lateral substituent effects on UV stability of high-birefringence liquid crystals with the diaryl-diacetylene core: DFT/TD-DFT study. Liq. Cryst. 2017, 44, 1515-1524. [CrossRef]

33. Ahmed, H.A.; Hagar, M.; El-Sayed, T.H.; Alnoman, R.B. Schiff base/ester liquid crystals with different lateral substituents: Mesophase behaviour and DFT calculations. Liq. Cryst. 2019, 46. [CrossRef]

34. Hagar, M.; Ahmed, H.A.; Saad, G.R. Mesophase stability of new Schiff base ester liquid crystals with different polar substituents. Liq. Cryst. 2018, 45, 1324-1332. [CrossRef]

35. Ahmed, H.A.; Mansour, E.; Hagar, M. Mesomorphic study and DFT simulation of calamitic Schiff base liquid crystals with electronically different terminal groups and their binary mixtures. Liq. Cryst. 2020, 47, 2292-2304. [CrossRef]

36. Hagar, M.; Ahmed, H.; Alhaddadd, O. DFT Calculations and Mesophase Study of Coumarin Esters and Its Azoesters. Crystal 2018, 8, 359. [CrossRef]

37. Hagar, M.; Ahmed, H.; Saad, G. Synthesis and mesophase behaviour of Schiff base/ester 4-(arylideneamino)phenyl-4"-alkoxy benzoates and their binary mixtures. J. Mol. Liq. 2019, 273, 266-273. [CrossRef]

38. Paterson, D.A.; Gao, M.; Kim, Y.-K.; Jamali, A.; Finley, K.L.; Robles-Hernández, B.; Diez-Berart, S.; Salud, J.; de la Fuente, M.R.; Timimi, B.A. Understanding the twist-bend nematic phase: The characterisation of 1-(4-cyanobiphenyl-4'-yloxy)-6-(4cyanobiphenyl-4'-yl) hexane (CB6OCB) and comparison with CB7CB. Soft Matter 2016, 12, 6827-6840. [CrossRef] [PubMed]

39. Sarkar, D.D.; Deb, R.; Chakraborty, N.; Mohiuddin, G.; Nath, R.K.; Nandiraju, V.R. Cholesterol-based dimeric liquid crystals: Synthesis, mesomorphic behaviour of frustrated phases and DFT study. Liq. Cryst. 2013, 40, 468-481. [CrossRef]

40. Majumdar, K.C.; Mondal, S.; Sinha, R.K. Synthesis and characterization of novel cholesterol based mesogenic compounds using 'click' chemistry. New J. Chem. 2010, 34, 1255-1260. [CrossRef]

41. Ibrahim, M.F.; Senior, S.; El-Atawy, M.A.; El-Sadany, S.K.; Hamed, E.A. DFT calculations of 2,4,6-trinitrophenylbenzoate derivatives: Structure, ground state properties and spectral properties. J. Mol. Struct. 2011, 1006, 303-311. [CrossRef]

42. Omar, A.Z.; Mahmoud, M.N.; El-Sadany, S.K.; Hamed, E.A.; El-Atawy, M.A. A combined experimental and DFT investigation of mono azo thiobarbituric acid based chalcone disperse dyes. Dyes Pigments 2021, 185, 108887. [CrossRef]

43. El-Atawy, M.A.; Hegazi, A.H.; Al Khalaf, M.; Amer, A. The structure elucidation of the isomeric mixture of 3-[L-threo-2,3,4-tri hydroxy-1-(phenyl-hydrazono)butyl] quinoxalin-2(1H)-one in dimethyl sulfoxide solution revisited: Experimental and theoretical study. Struct. Chem. 2020, 31, 1065-1072. [CrossRef]

44. Cruickshank, E.; Salamończyk, M.; Pociecha, D.; Strachan, G.J.; Storey, J.; Wang, C.; Feng, J.; Zhu, C.; Gorecka, E.; Imrie, C.T. Sulfur-linked cyanobiphenyl-based liquid crystal dimers and the twist-bend nematic phase. Liq. Cryst. 2019, 46, 1595-1609. [CrossRef]

45. Hird, M. Fluorinated liquid crystals_Properties and applications. Chem. Soc. Rev. 2007, 36, 2070-2095. [CrossRef] [PubMed] 
46. Sun, G.; Chen, B.; Tang, H.; Shi, G.; Xu, S. Synthesis and physical properties of laterally fluorinated liquid crystals containing 1,3,2-dioxaborinane and cyclohexyl units. Liq. Cryst. 2004, 31, 1151-1158. [CrossRef]

47. Matharu, A.S.; Cowling, S.J.; Wright, G. Laterally fluorinated liquid crystals containing the 2,2'bithiophene moiety. Liq. Cryst. 2007, 34, 489-506. [CrossRef]

48. El-Atawy, M.; Alhaddad, O.A.; Ahmed, H.A. Experimental and geometrical structure characterizations of new synthesized laterally fluorinated nematogenic system. Liq. Cryst. 2021. [CrossRef]

49. Saccone, M.; Kuntze, K.; Ahmed, Z.; Siiskonen, A.; Giese, M.; Priimagi, A. Ortho-Fluorination of azophenols increases the mesophase stability of photoresponsive hydrogen-bonded liquid crystals. J. Mater. Chem. C 2018, 6, 9958-9963. [CrossRef]

50. Altowyan, A.S.; Mostafa, A.M.; Ahmed, H.A. Effect of liquid media and laser energy on the preparation of Ag nanoparticles and their nanocomposites with Au nanoparticles via laser ablation for optoelectronic applications. Optik 2021, 241, 167217. [CrossRef]

51. Mishra, R.; Hazarika, J.; Hazarika, A.; Gogoi, B.; Dubey, R.; Bhattacharjee, D.; Singh, K.N.; Alapati, P.R. Dielectric properties of a strongly polar nematic liquid crystal compound doped with gold nanoparticles. Liq. Cryst. 2018, 45, 1661-1671. [CrossRef]

52. Zaki, A.A.; Ahmed, H.; Hagar, M. Impact of fluorine orientation on the optical properties of difluorophenylazophenyl benzoates liquid crystal. Mater. Chem. Phys. 2018, 216, 316-324. [CrossRef]

53. Al-Mutabagani, L.A.; Alshabanah, L.A.; Ahmed, H.A.; Gomha, S.M.; Abolibda, T.Z.; Shaban, M. Synthesis, Mesomorphic and Electrical Investigations of New Furan Liquid Crystal Derivatives. Front. Chem. 2021. [CrossRef]

54. Hagar, M.; Ahmed, H.A.; Alnoman, R.B.; Jaremko, M.; Emwas, A.-H.; Sioud, S.; Abu Al-Ola, K.A. New Liquid Crystal Assemblies Based on Cyano-Hydrogen Bonding Interactions. Front. Chem. 2021, 9, 9. [CrossRef]

55. Al-Mutabagani, L.; Alshabanah, L.; Ahmed, H.; Alalawy, H.; Al Alwani, M. Synthesis, Mesomorphic and Computational Characterizations of Nematogenic Schiff Base Derivatives in Pure and Mixed State. Molecules 2021, 26, 2038. [CrossRef]

56. Sultan, A.M.; Fahmi, A.A.; Saad, G.R.; Naoum, M.M. Effect of orientation of extra fused benzene ring and lateral methyl substituent on the mesophase behaviour of three-ring azo/ester molecules. Liq. Cryst. 2019, 46, 2269-2280. [CrossRef]

57. Ester, D.F.; Williams, V.E. Exploiting molecular symmetry reduction to enrich liquid crystal phase diversity. Liq. Cryst. 2019, 46, 1505-1516. [CrossRef]

58. Walker, R.; Majewska, M.; Pociecha, D.; Makal, A.; Storey, J.M.; Gorecka, E.; Imrie, C.T. Twist-Bend Nematic Glasses: The Synthesis and Characterisation of Pyrene-based Nonsymmetric Dimers. ChemPhysChem 2021, 22, 461-470. [CrossRef]

59. Ahmed, H.A.; El-Atawy, M.A. Synthesis, Mesomorphic and Geometrical approaches of New non-symmetrical System based on central Naphthalene moiety. Liq. Cryst. 2021. [CrossRef]

60. El-Atawy, M.A.; Naoum, M.M.; Al-Zahrani, S.A.; Ahmed, H.A. New nitro-laterally substituted azomethine derivatives; Synthesis, mesomorphic and computational characterizations. Molecules 2021, 26, 1927. [CrossRef] [PubMed]

61. Al-Zahrani, S.A.; Ahmed, H.A.; El-Atawy, M.A.; Abu Al-Ola, K.A.; Omar, A.Z. Synthetic, Mesomorphic, and DFT Investigations of New Nematogenic Polar Naphthyl Benzoate Ester Derivatives. Materials 2021, 14, 2587. [CrossRef]

62. Gray, G.W. Molecular Structure and the Properties of Liquid Crystals; Academic Press: London, UK, 1962.

63. Imrie, C.T.; Taylor, L. The preparation and properties of low molar mass liquid crystals possessing lateral alkyl chains. Liq. Cryst. 1989, 6, 1-10. [CrossRef]

64. Chan, T.-N.; Lu, Z.; Yam, W.; Yeap, G.-Y.; Imrie, C.T. Non-symmetric liquid crystal dimers containing an isoflavone moiety. Liq. Cryst. 2012, 39, 393-402. [CrossRef]

65. Henderson, P.; Niemeyer, O.; Imrie, C. Methylene-linked liquid crystal dimers. Liq. Cryst. 2001, 28, 463-472. [CrossRef]

66. Lee, H.-C.; Lu, Z.; Henderson, P.A.; Achard, M.F.; Mahmood, W.A.K.; Yeap, G.Y.; Imrie, C.T. Cholesteryl-based liquid crystal dimers containing a sulfur-sulfur link in the flexible spacer. Liq. Cryst. 2012, 39, 259-268. [CrossRef]

67. Imrie, C.T.; Karasz, F.E.; Attard, G.S. Comparison of the mesogenic properties of monomeric, dimeric, and side-chain polymeric liquid crystals. Macromolecules 1993, 26, 545-550. [CrossRef]

68. Donaldson, T.; Staesche, H.; Lu, Z.; Henderson, P.; Achard, M.; Imrie, C. Symmetric and non-symmetric chiral liquid crystal dimers. Liq. Cryst. 2010, 37, 1097-1110. [CrossRef]

69. Henderson, P.; Imrie, C.T. Methylene-linked liquid crystal dimers and the twist-bend nematic phase. Liq. Cryst. 2011, 38, 1407-1414. [CrossRef]

70. Alamro, F.S.; Ahmed, H.A.; Gomha, S.M.; Shaban, M. Synthesis, mesomorphic and solar energy characterizations of new nonsymmetrical Schiff base Systems. Front. Chem. 2021. [CrossRef]

71. Popoola, S.A.; Almohammedi, A.R.; Haruna, K. Spectroscopic and DFT evaluation of the positional effect of amino group on the properties of aminobenzenesulphonic acid: Solvents interactions. Chem. Pap. 2021, 75, 2775-2789. [CrossRef]

72. Davies, M. Some Electrical and Optical Aspects of Molecular Behaviour: The Commonwealth and International Library: Chemistry Division; Elsevier: Amsterdam, The Netherlands, 2014.

73. Sıdır, I.; Sıdır, Y.G.; Kumalar, M.; Taşal, E. Ab initio Hartree-Fock and density functional theory investigations on the conformational stability, molecular structure and vibrational spectra of 7-acetoxy-6-(2,3-dibromopropyl)-4,8-dimethylcoumarin molecule. J. Mol. Struct. 2010, 964, 134-151. [CrossRef]

74. Al-Mutabagani, L.A.; Alshabanah, L.A.; Ahmed, H.A.; El-Atawy, M.A. Synthesis, Optical and DFT Characterizations of Laterally Fluorinated Phenyl Cinnamate Liquid Crystal Non-Symmetric System. Symmetry 2021, 13, 1145. [CrossRef]

75. Alamro, F.S.; Ahmed, H.A.; Popoola, S.A.; Altaleb, H.A.; Abu Al-Ola, K.A.; Gomha, S.M. Effect of the Relative Positions of Di-Laterally Substituted Schiff Base Derivatives: Phase Transition and Computational Investigations. Crystals 2021, 11, 870. [CrossRef] 